\title{
URBAN TOURISM RESEARCH
}

\section{DEVELOPING AN AGENDA}

\author{
Dr Deborah Edwards \\ University of Technology Sydney Australia
}

Tony Griffin

University of Technology Sydney Australia

Associate Professor Bruce Hayllar

University of Technology Sydney Australia

\begin{abstract}
The study of urban tourism and associated focus on urban tourist precincts is a growing area of interest as practitioners, researchers and policy makers seek to understand the phenomenon of tourism within the urban environment. In Australia research in this area has lacked integration and has not engaged sufficiently with the contextual setting of the urban environment. This paper reports on a study that was undertaken to identify the important areas that should be included in an urban tourism research agenda. This paper has three aims: to review the literature on urban tourism; to outline the process that was undertaken to identify areas for urban tourism research; and to present a conceptual framework that can be used to focus future urban tourism research.
\end{abstract}

Keywords: urban tourism, research agenda, framework

Dr Deborah Edwards is the STCRC Senior Research Fellow in Urban Tourism in the School of Leisure, Sport and Tourism at the University of Technology, Sydney. Deborah's interests are in sustainable tourism management, urban attractions, community volunteers in tourism and the social impacts of events. Deborah is on the executive committee of the Best Education Network (BESTen). Postal: PO Box 222, Lindfield, 2070, Australia. Email: deborah.edwards-1@uts.edu.au

Tony Griffin is a Senior Lecturer in Tourism Management in the School of Leisure, Sport and Tourism at the University of Technology, Sydney. Tony has published extensively on subjects such as sustainable tourism, urban tourism precincts and tourism in national parks. Much of this research has focused on understanding the nature of tourist experiences.

Associate Professor Bruce Hayllar is Head of the School of Leisure, Sport and Tourism at the University of Technology, Sydney. Bruce has an extensive portfolio of applied research projects for both the public and private sectors with a particular interest in the experience of people in learning and leisure environments. His research interests are in urban tourism, tourism precincts and camping and caravanning. 


\section{INTRODUCTION}

Urban environments worldwide have for many years been amongst the most significant of all tourist destinations. As Karski explains:

Urban tourism has, in one form or other, been with us since Mesopotamia and Sumeria were spawning the phenomenon of urbanization. People with the means and inclination to do so have been drawn to towns and cities just to visit and experience a multiplicity of things to see and do...These (towns and cities) were the melting pots of national culture, art, music, literature and of course magnificent architecture and urban design. It was the concentration, variety, and quality of these activities and attributes ... that created their attraction and put certain towns and cities on the tourism map... (Karski 1990, p. 15).

Today tourism consumes substantial amounts of space within urban destinations: tourist-historic urban cores, special museums of many kinds, urban waterfronts, theme parks and specialized precincts all contribute to this consumption (Gospodini 2001). Major urban areas perform important functions within the workings of the overall tourism system: for example, they are key "gateways" for both international and domestic tourists and, as key nodes in the air transport system, act as staging posts for multi-destination trips. Many of these functions are often taken for granted and, as a consequence, the requirements for profitable and sustainable tourism development in urban areas are not well understood. While urban tourism has been subject to some research attention in recent years, this effort has arguably not reflected its degree of importance relative to tourism in other types of destinations.

Urban tourism is distinguishable from other forms of tourism by a number of features which, while they are not applicable to all urban destinations and may be applicable to some non-urban destinations, characterize urban tourism destinations as a whole. Significant numbers of tourists in urban areas are visiting for a primary purpose other than leisure, including business, conferences, shopping, and visiting friends and relatives. Local residents (and commuters) are also significant (often majority) users of attractions and of infrastructure which has generally been developed for non-tourism purposes. Within urban destinations often the number, variety and scale of primary and secondary attractions are large. A particularly distinguishing characteristic of tourism in an urban context is that it is just one of many economic activities within a city and it must compete with a number of other industries for resources such as labor and land. This has implications for the awareness and perceived importance of issues related to tourism amongst business, government and residential communities. Consequently planning and policy-making processes and even the day-to-day operational management of tourism activities are made more complex by the necessary engagement between tourism and the multiplicity of public and commercial organizations with varying levels of involvement with tourism in urban areas. These complex processes have further implications for the coherence of marketing activity. Finally, within urban areas there is a complex mix of constraints on development, with natural environmental factors being generally less significant and cultural heritage and residential factors more significant than in other forms of tourism.

Law (1996) outlines a number of key attributes that urban areas possess as tourist destinations. They have naturally large populations which in turn attract visiting friends and relatives. They draw tourists to their attractions because these are often much better developed than in other types of destinations. They are easily 
accessible through airports and scheduled services. There is a large stock of accommodation built to serve the business traveller and finally, urban destinations appeal to a number of different tourist markets as they offer the communications, transport, services and facilities which meet tourist needs. These markets include: a more educated population, which is attracted to the cultural heritage of cities and towns; seniors, who undertake more sightseeing and are more likely to appreciate cultural and historic heritage; young people, who are attracted by the excitement of the urban environment along with entertainment, night life and sporting events; business travelers; and the meetings, incentives, conventions and exhibition market.

It is the complexity of the elements listed above in conjunction with the potential economic, social and environmental impacts which result from visitation that makes urban tourism research essential. In light of this, there is a need for more strategic and cohesive research. Developing a research agenda that can result in the provision of guidance to the industry on how to more effectively develop, manage and market urban tourism destinations is important to the long-term sustainability of tourism in these settings. However, gven the large number of possible research questions, an agenda that prioritizes research can be useful for researchers, educators, policymakers and potential sponsors of any future research. The purpose of this paper is to advance research in urban tourism by presenting a considered and interrelated approach.

\section{URBAN TOURISM RESEARCH AND CONTEXT}

As urban tourism brings together people, place and consumption, and mixes cultures, values, expectations and experiences, it provides an exciting landscape for exploration. Prior to the 1980s, research on urban tourism was fragmented and not recognized as a distinct field. Among the early studies were: Burgess (1975); Pearce (1977) based on Lynch's (1960) ideas on city imaging; Blank and Petkovich (1979); and Judd and Collins (1979). References to urban tourism as a distinct phenomenon and area of research began to appear in the literature in the 1980s. Vandermey (1984) points out that of all tourism types, urban tourism is one of the most misunderstood and underestimated. Hall (1987) draws attention to the potential for tourism to contribute to the regeneration of declining industrial urban centres, and Pearce (1987) notes the dearth of research on urban tourism. But the paper which appears to have sparked an upsurge of interest in the topic is Ashworth's (1989, p.

33) "Urban tourism: an imbalance in attention” in which he states:

There has been quite simply a rural bias noticeable in both the quantity of the literary output and the quality of the theorizing about tourism. This is in itself remarkable because most tourists originate from cities, many seek out cities as holiday destinations and the social and economic impacts of tourism are substantial in urban areas. Thus the failure to consider tourism as a specifically urban activity imposes a serious constraint that cannot fail to impede the development of tourism as a subject of serious study (1989:33).

Eleven years later, there is a growing volume of published work. In particular there has been an increase in the number of books, mostly edited collections, which have now been published on the topic including Ashworth and Tunbridge (1990; 2000); Page (1995); Law (1993; 1996); Van den Burg, Van der Borg and Van der Meer (1995); Murphy (1996); Grabler, Maier, Mazanec and Wöber (1997); Tyler, Guerrier and Robertson (1998); Judd and Fainstein (1999); Orbasli (2000); and Hayllar, Griffin and Edwards (2008). 
Taken together, the research literature in addition to general theory/delineation of urban tourism covers a number of topics, some of which are unique to urban tourism or are primarily urban phenomena and some of which are common to a number of forms of tourism but may take on particular characteristics in an urban context. Topics which have as a primary focus urban phenomena include heritage conservation, urban structure and infrastructure of tourism precincts, regeneration of the inner city and waterfronts, and those activities conducted specifically in urban contexts, such as big city shopping, the arts, gambling/casinos and eating out. Topics that are more generic include festivals and events, cultural, economic and social impacts, tourist attitudes and destination marketing.

\section{Defining Urban}

What is urban tourism and how does it differ from tourism in general? Many countries typically designate areas as "urban" when a certain population size or population density is reached. For example the United Nations (1968) defines an urban area as one with more than 20,000 people. Although these numbers provide useful boundaries they are somewhat arbitrary and incur problems. For example, is an area with 20,000 people or 999 people substantially different from a major urban or other urban setting? No single population cut-off is likely to be ideal for all situations. Statistics New Zealand (2006) uses six criteria for identifying an urban boundary, viz: 1) strong economic ties; 2) cultural and recreational interaction; 3) serviced from the core for major business and professional activities; 4) an integrated public transport network; 5) significant workplace commuting to and from the central core; and 6) planned development within the next 20 years, as a dormitory area to, or an extension of, the central core. Taken together these six criteria suggest that urban areas are primarily signified by a busy, interactive built environment purposely developed to meet the needs of many stakeholders.

Not too dissimilar to numbers of people, urban ecologists view "urban" as being at the opposite end of a spectrum to "natural". "Urban" is characterized by the presence of humans and "natural" by the absence of humans (McIntyre, K Knowles-Ya' Nez and Hope 2000). Distance from the urban centre is used as an initial cut for determining whether spatial correlations exist between increasing human activity and natural environments. However, urban areas consist of multiple cores, have hard boundaries, and more commonly can grow by rapid, leapfrog development over remnants of undeveloped open space (McIntyre, K Knowles-Ya' Nez and Hope 2000).

The social sciences (including, but not limited to, anthropology, political science, economics, planning, sociology and environmental psychology) offer additional elements to understanding urban environments. Economists see urban as based on human population density within a given political unit (McIntyre, K Knowles-Ya' Nez and Hope 2000) that is characterized by non-extractive occupations that benefit particularly from a high population density and the accompanying infrastructure and processes that produce them. Sociologically, “urban” may typify wider, but less personal social relations and a lifestyle characterized by individualism, anonymity and a segmentation of life. Fainstein (1994) writes that urban areas consist of both people and their homes, offices and factories which shape social relations, causing demographic commonalities 
to assume spatial identities. She adds that these social groups then imprint themselves physically onto the urban structure affecting the formation of communities, competition for territory, and segregation. Taken together the approaches discussed thus far may specify what constitutes urban but not what distinguishes its essential character.

McIntyre, Knowles-Yánez and Hope (2000) argue that humans perceive and react differently to natural versus urban settings. Scenes of natural environments have a more positive influence on human emotional states and stress levels than do urban scenes. Consequently they theorize that perceptions are integral to people's motivations and actions; therefore using a perceptually based definition of urban can provide a link between the cultural, political, physical, perceptual and economic aspects that must be integrated into urban tourism. If, as they argue, “the definition of urban incorporated perceptual variables known to be salient to a person's discrimination between urban and natural environments”, (McIntyre, K Knowles-Yánez and Hope 2000, p. 13), then such a definition could assist the interdisciplinary nature of urban tourism.

Drawing on this discussion, and for the purposes of this study, urban is defined as a place that possesses the following elements: a strong and broad economic base that is serviced from multiple cores for major business and professional activities; a significant public transport network that acts as a gateway to other areas; a significant population with a workforce that commutes to and from the multiple cores; and long-term planned development. This functional and physical environment is characterised by a perception that the urban landscape is a web in which many individuals and groups have social, cultural, political and economic relationships.

\section{Analysing Urban Tourism}

A number of noteworthy contributions have been made to the analysis of urban tourism. In a seminal paper, Ashworth (1989) outlines four extant approaches to analyzing urban tourism, reflecting, as he admits, a geographical bias. First, the facility approach takes into account the spatial analysis of the location of tourism attractions, facilities, infrastructure and zones - including transport routes, hotels, and historic and business zones. Second, the ecological approach focuses on studying the structure or morphology of urban areas, which are seen to evolve and function in both a systematic and an organic way. A feature of this approach is the identification of functional zones or districts (eg CBD, historic core, markets area, industrial area), which links with the contemporary idea of tourism precincts. Third, the user approach focuses on the characteristics, activities, motivations, purposes and attitudes of tourists - particularly related to tourism marketing. Fourth, policy approaches arise from the concerns of city governments to accommodate and/or promote tourism by focusing on a range of policy issues, including infrastructure provision and destination marketing.

Blank (1994) adopts a functional approach, presenting a list of urban tourism research issues which could apply to any environment: impact, marketing, tourism facility management and personnel training needs, resident attitudes and tourism plant. A broader intellectual perspective is taken by Fainstein and Gladstone (1997), who divide urban tourism research into just two types: the political economy approach and the cultural approach. The political economy approach "assesses the contribution of tourism to urban and regional economies and to the well-being of residents of the place being visited” (p. 120). The cultural approach is 
concerned with impacts on the traveller; it emphasizes the symbolic aspects of tourism and asks: "what is the meaning of tourism for the (post)modern world?” (p. 121).

Page (1996) suggests a systems framework for analyzing urban tourism, but does not develop the idea fully. Pearce (2001) contributes a supply-side approach, involving the examination of a set of issues (demand, supply, development, marketing, planning, organization, operations and impact assessment) at each of a range of spatial scales (city-wide, district, site). His argument is that the nature of supply will "vary from one scale to another along with changes in responsibility for policymaking, management, operations, and other practical applications” (p. 929).

Borrowing from and adapting the above typologies, the authors believe that approaches to analysing urban tourism can be divided into three perspectives: urban planning/governance, industrial and cultural. An urban governance perspective views tourism as just one among the many social and economic "players" in the city, competing for space and contributing to economic activity. From this perspective, regional and city governments are faced with the challenge of promoting, accommodating and controlling tourism alongside other urban activities. The industrial perspective sees tourism as an industry, with a range of products to sell, markets to identify and access, investments to be undertaken, product distribution to be managed, and profits to be made. The cultural perspective, as outlined by Fainstein and Gladstone (1997), is represented in Figure 1 and is concerned with the place of tourism in a changing culture and with broader contextual issues such as globalization, postmodernization and cultural imperialism. Within the cultural perspective there are two important foci. Firstly, there are the impacts that tourists have on the host destination as they move around a city, occupy spaces, consume resources, engage in activities and interact with the community. A particular concern is the manner in which tourists effect changes in host communities' collective and individual value systems, behavior, patterns, community structure, lifestyle and quality of life. The second focus is the tourist experience itself and the way in which travel to an urban destination affects tourists' motivations, preferences and cultural perspectives, which subsequently shape their future travels and world views. Tourist experiences are not seen as a one-sided phenomenon.

\section{Insert Figure 1 Here}

The above perspectives are mutually inclusive. To plan, regulate and facilitate effectively, governments require an understanding of the functioning and needs of the various stakeholders in the urban environment. In the case of tourism, governments are often part of the industry, as owners and operators of infrastructure and attractions and through organizations such as tourism boards and convention and visitors' bureaux. Similarly, the industry can only operate effectively in cooperation with government and in recognition of community values. The cultural perspective, although historically seen as "standing apart" from the operational aspects of tourism, is increasingly recognized as being integral to tourist experiences and provides useful information on social trends and the likely long-term impact of tourism on host urban cultures.

In this context urban tourism is defined as one among many social and economic forces in the urban environment. It encompasses an industry that manages and markets a variety of products and experiences to 
people who have a wide range of motivations, preferences and cultural perspectives and are involved in a dialectic engagement with the host community. The outcome of this engagement realizes a set of consequences for the tourist, the host community and the industry.

Given the manifestly complex nature of urban tourism, and the limited scope of existing research, this study focuses on the development of a research agenda that can guide the industry on how to more effectively develop, manage and market urban tourism destinations. Underlying this agenda is the need to ensure the longterm sustainability of tourism in those settings. The question - "what are the important areas that should be included in an urban tourism research agenda for improving the performance of Australian urban tourism destinations?"- was used to guide this agenda setting process. The notion of “performance” encompasses the perspectives of a wide range of stakeholders; from profit-motivated industry to government and community groups that might be more concerned with public good and quality of life issues. While it was conducted in an Australian context, the answers to the above question have broader, global application.

\section{Study Methods}

The study was conducted over six months using a range of methodologies within a four-stage process, as represented in Figure 2. Stage One involved a scoping workshop to identify an initial set of urban tourism research issues which could feed into Stage Two. Stage Two was an international Delphi study of academics with an interest in urban tourism. To ensure that the eventual research agenda was relevant to the industry, Stage Three involved focus groups with a broad range of industry representatives. Finally, the findings from each stage were drawn together and analyzed as a whole. The study was an ongoing process, one in which the researchers iteratively theorized and tried to make sense of the data as the study progressed.

Insert Figure 2 Here

Stage One - Workshop. Stage One involved a workshop held at the conference of the Council for Australian University Tourism and Hospitality Education in February 2006. This workshop was conducted using the nominal group technique (NGT) developed by Delbecq, Van de Ven and Gustafson (1975), as a consensusbuilding tool to assist in identifying and prioritizing a research focus. NGT involves six steps: statement of the problem; restatement of the problem by participants; silent generation of ideas; round robin collection of ideas; clarification of ideas; and selection and ranking of ideas. Presbury and Edwards (2005) report a number of advantages in using the NGT, viz: there is a greater possibility for generating multiple ideas because each person has time to consider the issues in depth and thus can be creative in their thinking; as everyone is given a structured opportunity to participate there is less likelihood that important issues, new approaches and fresh perspectives are missed; the process helps to overcome common problems of other workshop methods, such as the dominance of proceedings by more confident or outspoken individuals; it produces results with relatively few resources; and participants quickly learn that process and decisions can be made at the close of the session, which makes it relatively efficient.

There were ten participants in the workshop including the facilitators. The guiding question was "What are the important areas that should be included in the development of an urban tourism research agenda which can 
improve the performance of Australian urban tourism destinations?". The workshop identified a total of 46 issues. To prioritize the issues, each participant was given a total of six points which they could allocate to the issue/s they considered to be most important. Points could be assigned in any way, ranging from allocating single points to six different issues or all six points to one issue. At this stage participants also chose to group the 46 issues under six common themes: impacts; experience and behaviour; destination development and management; spatial relationships; design; and economic. Following the workshop, issues were reworded to ensure consistency and avoid any potential confusion in the following stages of the study.

Stage Two - Delphi Study. In Stage Two, an online Delphi Study was used. "The Delphi technique is widely recognized to represent a very flexible research method, and one that can lend an added dimension of rigor to addressing the kinds of questions and issues that are difficult to research” (Garrod and Fyall 2005, p. 85). The technique eliminates physical group interaction and systematically combines expert knowledge and opinion to arrive at an informed group consensus (Rowe and Wright 2002). This takes place through the careful design of sequential questionnaires which are interspersed with summarized information and feedback of opinions derived from previous responses (Delbecq, Van de Ven A. H. and Gustafson 1975). No firm rule governs the number of panelists. Rowe and Wright (2002) believe that panels should comprise between 5 and 20 experts. Garrod and Fyall (2005) do not consider panel size to be a critical issue. Delbecq, Van de Ven and Gustafson (1975) suggest that few new ideas are generated within a homogenous group once the size exceeds 30 participants.

The Delphi technique is essentially a series of questionnaires. The process begins with a general questionnaire which acts to explore the subject under consideration, asking each participant to contribute any information he/she feels is pertinent to the study (Linstone and Turoff 1975). This information is used, in addition to information compiled by the facilitator, to form the second-round questionnaire. Each subsequent questionnaire is built upon responses to the preceding questionnaire. At each stage, a summarized group opinion is fed back to participants. This process serves to remind individuals of their own previous responses and to ask them to reconsider their opinions. Over successive rounds, the distribution of responses narrows toward convergence. There is no firm consensus on the optimal number of structured rounds but the accepted criterion is "when responses show stability, and it is up to the facilitator to decide when to call the procedure to a halt” (Rowe and Wright 2002, p. 131). Time and money constraints suggest it is practical to end the process after three or four rounds. To avoid ambiguity in both questions and items (Garrod and Fyall 2005) a pilot of the initial questionnaire was conducted with 10 tourism colleagues from New South Wales (Australia) universities.

Australian and international academics with a research interest, skill and knowledge in the broad field of urban tourism were targeted for the Delphi study. An initial invitation was sent to 25 academics asking them to participate, of whom 15 agreed. The Delphi comprised three rounds. The response rate for rounds one, two and three were $100 \%, 73 \%$ and $80 \%$ respectively. There was a higher response rate for the final round as one participant who was unable to contribute to round two, due to work commitments, wanted to contribute to round three. Complete anonymity of participants was maintained. 
In accordance with Rowe and Wright (2002) the first round of the questionnaire was somewhat unstructured. Round one sought opinions on the 46 issues that were identified in Stage One. Participants were asked if they agreed, disagreed or didn't know whether an issue should be included in a research agenda. They were also invited to suggest additional issues which they considered to be worthy of inclusion. As a result, participants identified another 17 issues for inclusion in successive rounds. None of the original issues was considered unworthy of inclusion in the research agenda. In round two, participants were asked to rank the 63 issues on a Likert scale, with one (1) being extremely important and seven (7) being extremely unimportant. In round three participants were provided with a simple statistical summary of the group response from round two in addition to their individual response and invited to reassess this in relation to the group's response. Only three participants chose to change their responses, with one making substantive changes and the others very minor changes: the panel was not going to move towards further consensus.

Stage Three - Industry Consultation. In order to identify a research agenda that would have value and relevance to the industry, the research group actively engaged industry in the agenda-setting process. Consequently three industry focus groups were held during May and June 2006, which explored the research needs of government and industry organizations with an interest in the broad area of urban tourism.

Focus group discussion is the process of obtaining possible ideas or solutions to a problem from a group of respondents by discussing it (Aaker, Kumar and Day 2003). Focus groups are a flexible method that can be used in a variety of contexts and within a whole range of research paradigms. They are particularly effective in capturing complexities within a given context and exploring how participants value and define key concepts in their own words (Thomas 2004). According to Gomm (2004, p. 172) "the hallmark of focus groups is the explicit use of group interaction to produce data and insights that would be less accessible without the interaction found in a group”. Most focus groups consist of between 6 to 12 people. Merton, Fiske and Kendall (1990, p. 137) suggest the "size of the focus group should not be so large as to be unwieldy or to preclude adequate participation by most members nor should it be so small that it fails to provide substantially greater coverage than that of an interview with one individual”. Krueger (1998) argues that in order for the group to be small enough to permit genuine discussion among all participants 6 to 8 people per group is preferred.

A broad range of industry and government representatives were invited to take part in the focus groups. A total of 24 individuals participated in three focus groups which each ran for approximately two hours. The focus groups served three purposes: firstly, to capture research issues that were specific to the different sectors within the industry; secondly, through discussion and consensus building to gain an indication of the issues of most importance to industry; and lastly, to determine whether the top ten issues identified by academics in Stage Two had relevance for the industry.

To initiate the discussion participants were asked the open-ended question, "From your industry perspective what do you think are the important issues that should be included in an urban tourism research agenda for improving the performance of Australian urban tourism destinations?”. Two assistant moderators took written notes during the session recording participant's responses. All moderators took on the task of clarifying 
comments or where necessary probing for further information. Participants were asked at the conclusion of the focus groups to state what they perceived to be the single most important research issue for their industry sector. Although time did not allow a ranking of the issues identified by the focus groups, each participant was asked to rank the top ten issues identified from the Delphi study.

Stage Four - Data Analysis. Information collected from the workshop and focus groups were collated into individual reports immediately following the sessions. Participants from the focus groups were sent a copy of the report of their respective session and asked to verify that the outcomes of the discussion had been recorded accurately and to make any additional comments. A content analysis was undertaken of the combined narratives from the focus groups and workshops and a thematic analysis undertaken. Quantitative data collected in Stage Two were analyzed using SPSS version 12.0.1.

\section{Findings}

The CAUTHE workshop identified 46 issues which were perceived to be important areas of research for improving the performance of urban tourism destinations. Workshop participants grouped these issues into eight broad themes: impacts; experience and behavior; destination development and management; spatial relationships; design; economic; definitional; and methodology. The issues were used to form the basis for the Delphi study in Stage Two.

The top ten issues identified in the Delphi study come under four major themes: experience and behavior, impacts; spatial relationships; and destination development and management.

Insert Table 1 here

There is little difference in mean scores between the top three issues considered to be "very important": how tourists use cities; the patterns of behavior of tourists in urban environments; and environmental impacts in urban destinations. Similarly there is little difference between mean scores for the seven issues considered as "important": the influence of transport on tourist access; benefits of urban tourism; criteria for successful urban tourism development; carrying capacity; impacts; tourist dispersal; and benchmarking. The two issues ranked lowest were assessing national capital cities as distinct destinations; and the effect of globalization and homogenization of goods and services on tourist expenditure. Overall the minor differences in mean scores may be a reflection of participants' own self-related expertise (Murray 1979). Further, given the sample, it is likely that all research is perceived by academics to be of importance.

The industry-based focus groups identified some 240 specific research issues. Importantly the nature of the focus groups enabled a deeper analysis of industry research issues overall, and it was found that each issue aligned with one of the research themes identified at the CAUTHE workshop. For example the issues of planning, infrastructure, management, marketing, communication, benchmarking and product development could be included in destination development and management. Economic issues identified in Stage One were not perceived by participants to be impact-related but to have a more general economic focus around the distribution of economic benefits. Economic issues identified by industry incorporated both elements of a general nature and elements that were specifically impact-related. Subsequently economic issues were 
categorized under both the broad theme of economic issues and the more specific theme of impacts. The authors observed that there was little mention by industry of the environmental impacts of tourism on urban destinations. The experience and behavior theme was also divided into five sub-themes: motivation, tourist experience, quality, tourist expectations and tourist behavior. A theme that was not identified in either the CAUTHE workshop or the Delphi study was the effect of tourism trends on various sectors within tourism, i.e. events, water-based activities and product development.

In spite of the wide range of specific issues raised, there was a high degree of consensus amongst industry stakeholders on some essential issues. Firstly they emphasized the need for research to be conducted at a deeper level. They argued that there was now sufficient, broadly descriptive information on such things as purpose of visit, activities undertaken and broad economic impacts. What was required was more specific information about those who directly and indirectly benefited from tourism, why people choose certain urban tourism destinations over others, and what tourists actually do when they are in urban destinations. Secondly, improving planning practices at all levels was of major importance and a lack of coordinated planning was considered to be an inhibiting factor to the development of a quality-driven and efficient industry. Thirdly, accessibility in terms of moving around the city, between precincts and to urban tourism destinations was considered important and was a recurring issue within a number of themes, including planning, design, economic impacts and experience and behavior. Focus group participants wanted to better understand a broad range of questions, including: how infrastructure could be used to improve tourist access for a range of market segments, including the accessible tourism market; the access challenges that tourists encountered when moving around an urban destination; what type of signage was required for different tourist groups that would assist them to move around an urban destination; how accessibility, or the lack thereof, impacts on the tourist experience; and the relationship between airline access, tourist numbers and the resultant economic impacts.

Following the discussion on research issues participants were asked to state what issue they perceived as the most important. They identified 10 major issues which were: a better understanding of tourist experiences, motivations, perceptions and expectations; improved understanding of service delivery and quality; analysis of microeconomic impacts and key performance indicators; understanding the tourist information/communication delivery process; understanding differentiation and what makes the city experience distinctive; appraising tourists' public transport needs; assessing global planning requirements for the local community and tourists; identifying demand and infrastructure needs; identifying future trends in the meetings, incentives, conventions and exhibition sector with implications for future planning; and examining the impediments to government cooperation and coordination.

At the conclusion of the industry focus groups participants were asked to rank the top ten items identified in the Delphi study. This simple comparison did not indicate a high level of consensus between industry and academe. Although industry ratings partly reflect each participant's set of vested interests related to their industry sector overall, no items were ranked "very” important by industry. Items ranked between "important” and "somewhat important" were the influence of transport on tourist access, urban tourism benefits, successful urban tourism criteria, behavior patterns of tourists, and benchmarking. Items ranked between "somewhat 
important" and "neither important nor unimportant" were the impacts of tourists on the leisure experience of the local community, tourist use of cities, environmental impacts on urban destinations, carrying capacity, and tourist dispersal.

\section{Insert Table 2 here}

A final general observation by the authors was that the industry representatives professed a low level of awareness of the research data that could be available to them through various sources such as universities, national and state tourism authorities, industry associations and government organisations. In some respects industry came across as "information poor" in that they were not aware of the range of available research information, how and where it could be accessed, and subsequently what the information might mean for their particular business or industry sector. It was an indication that much more needs to be done by the academic community and other repositories of tourism research to improve the effective and efficient communication of research findings back to industry.

\section{A Strategic Framework for Urban Tourism Research}

The study identified an extremely diverse range of micro issues, with varying perspectives on the relative importance of these. Ultimately it was necessary to process this input such that all views could be captured. The outcome of this process was an overall research framework (Figure 3) that links and contextualizes the disparate issues identified through the workshop, Delphi and focus groups to guide the future direction of urban tourism research. It was found that the research issues could be grouped into a series of conceptual sets, principally comprising experience and behavior, impacts, linkages, and governance issues. The framework recognizes that tourism activity in urban environments is founded on certain attributes, features and places within the fabric of the city. These effectively represent a set of assets for tourism and its associated industry. Developing a research agenda that fosters sustainable developments of tourism in urban settings must then recognise the manifold ways in which these assets are significant: experiences are structured around these assets but excessive or inappropriate use can impact on their values; the industry relies upon them as the basis for generating income; and governance is associated with appropriately enhancing, protecting and managing those assets in the longterm public interest.

This framework assists with prioritising the urban tourism research issues that emerged from the agendasetting process. Each box encapsulates a key set of issues identified by participants in the study, while the overall framework identifies the relationships between the sets and suggests a logical order in which these sets of issues could be addressed. The arrows between boxes indicate the interrelationships between the general research areas as well as highlighting the instrumental value of each research area.

\section{Insert Figure 3 Here}

Issues consistently identified by both industry and academics were those associated with developing a better understanding of the tourist's experience and behavior. For all participants "experience and behaviour" represent a key foundation set of issues required to develop a better understanding of the urban tourist including inter alia tourist motivations, expectations, behavior, trends and communication. Participants considered these issues important for understanding both the impacts that occur in an urban destination and how this knowledge can inform key industry functions which serve the tourists' needs and meet their expectations. Fundamentally 
there is a need to understand the key elements that make up the urban tourism experience, how these elements are experienced by the tourist and how they determine the nature and location of tourist impactsenvironmentally, socially and economically.

Increasingly tourism has an influencing role in shaping the spatial and economic characteristics of urban environments. A clearer understanding of the issues of experience and behavior can assist in improving the economic and spatial structures of the industry that delivers various elements of the tourism experience. Specific issues raised by industry included what does the tourist actually consume as part of the urban tourist experience, what is the relative importance of each service encounter to the overall quality of experience, is the product matching expectations and how does the dispersal of tourists influence their experiences? Answers to such questions they argued was fundamental to improving the performance of significant service providers.

“Experience and behavior”, “impacts” and "linkages” are foundation issues that should influence and inform research on governance and planning issues and any subsequent decisions by management authorities. Workshop participants proposed that governance and planning should be primarily about improving outcomes for stakeholders, and research on the foundation issues is needed to ensure that these efforts are appropriately focused. Foundation research should provide an understanding of such matters as: the nature, magnitude and causes of current problems - for example unacceptable impacts or dissatisfied tourists; key determinants of tourist satisfaction in a variety of urban tourism settings; key infrastructural requirements for facilitating tourist experiences; how residential communities perceive tourism so that tourism can be developed and managed in ways that reflect community needs and concerns; and training requirements across a diverse range of service providers so that overall service quality is enhanced. For participants research that is focused on "benchmarking and best practice” can further inform and guide urban planning and governance by pointing to practices that have produced successful outcomes in the past.

Underlying the whole framework are the assets or resources of the destination on which tourism is founded, including the infrastructure and the natural and built environment which are available for use by tourists and the industry within the destination. Assets essentially drive tourism within the destination and represent the basis for generating income from tourism, both now and in the future. Industry issues that would sit within this box include understanding differentiation and what makes the city experience distinctive; the influence of transport access to and within the urban environment; and how tourism trends influence product development. Industry appreciated that different tourists will have their own perceptions of what the assets of an urban destination are and that these may be both tangible (in the case of attractive or historic buildings) and intangible (the atmosphere or friendliness of locals). Recognizing these assets, their value(s) and what gives assets value are basic requirements to appropriately developing and managing tourism in urban destinations. However, it is also important to recognize that such assets may well have value for reasons other than their utility in catering to tourists' needs. Assets, both tangible and intangible, may also be degraded or devalued by overexploitation or inappropriate behavior by tourists, the tourism industry, and other economic sectors. 
Ultimately the framework reflects industry's call for appropriate guidance on the governance of urban tourism destinations and the specific assets within them. It takes into consideration industry's perspective that this governance - policy, planning, design, management, marketing and communication activities - should be a whole of government approach that aims to achieve positive outcomes with respect to: improved experiences for the tourists; reduction of negative impacts; greater net benefits for the host community; and improved functioning of the total, interdependent industry within the urban environment. Hence while recommendations with regard to improved governance of urban tourism destinations must be informed by a fundamental understanding of tourist experiences and behavior, impacts and industry linkages, they must also feed back to and influence these elements in a positive way. In essence, these practices should be conceived as revolving around the long-term maintenance and effective functioning of the assets on which urban tourism is based. However, this is contingent on an understanding of what those assets comprise, what gives them value, how that value can be maximized and what threatens to diminish their value.

\section{CONCLUSION}

The idea of developing an urban tourism research agenda was intended to advance research in urban tourism in a considered and interrelated process, with the active engagement of stakeholders who have an interest in improving the performance of urban tourism destinations. This paper contains the outcomes of this study: a conceptual framework which is flexible in its application as it highlights, in a structured way, the research priorities identified by a cross-section of government and industry representatives coupled with the input of Australian and international tourism academics who have an interest in and knowledge of the broad field of urban tourism. The research agenda set out in this paper is by no means exhaustive; however, as representative of the Australian context it makes an important contribution to the growing body of literature on urban tourism. The research priorities identified reflect the views of the people and organizations who participated in this study.

The contrast between the views of industry and academia in relation to setting priorities for urban tourism research is interesting. Not surprisingly, industry placed most emphasis on those issues that could serve their direct commercial interests rather than reflecting the broader interests of other stakeholders, such as the environment. Impact issues, quite prominent in the view of academics, were perceived as far less important by industry, with the exception of identifying the benefits of tourism for local communities. Both points of view are valid, and should be considered in the formulation of any urban tourism research agenda that is focused on improving the performance of urban destinations. In the context of a broad issue like the sustainable development of urban tourism, the industry's priorities cannot be ignored if businesses are to remain competitive and viable. Perhaps not surprisingly, the academics' priorities acknowledge the need to consider the broader contextual issues of sociocultural and ecological sustainability as well. One matter on which there was general agreement concerns the knowledge gaps in urban tourism and the need for dedicated research in this rather neglected but highly significant area of tourism.

The study offers practical and useful guidance for investigating urban tourism. As an exploratory approach this study has enabled a range of micro issues to emerge which can be useful for informing future research. In line with Pearce (2001), the framework presented here is intended to provide structure but not act as a 
straightjacket, as well as form the basis for further conceptual and empirical work. For future research, foci incorporated within each set of issues can be chosen at two levels. Firstly, from an academic perspective research issues may be selected to fill the gaps in existing knowledge about urban tourism. Secondly, research issues can be chosen to address particular problems and challenges that an urban destination may be facing.

This paper has systematically addressed the need for a structured approach to urban tourism research. The framework outlined presents a way forward for such research, and effort can now be directed at further research that aims to understand these important issues in more depth. 


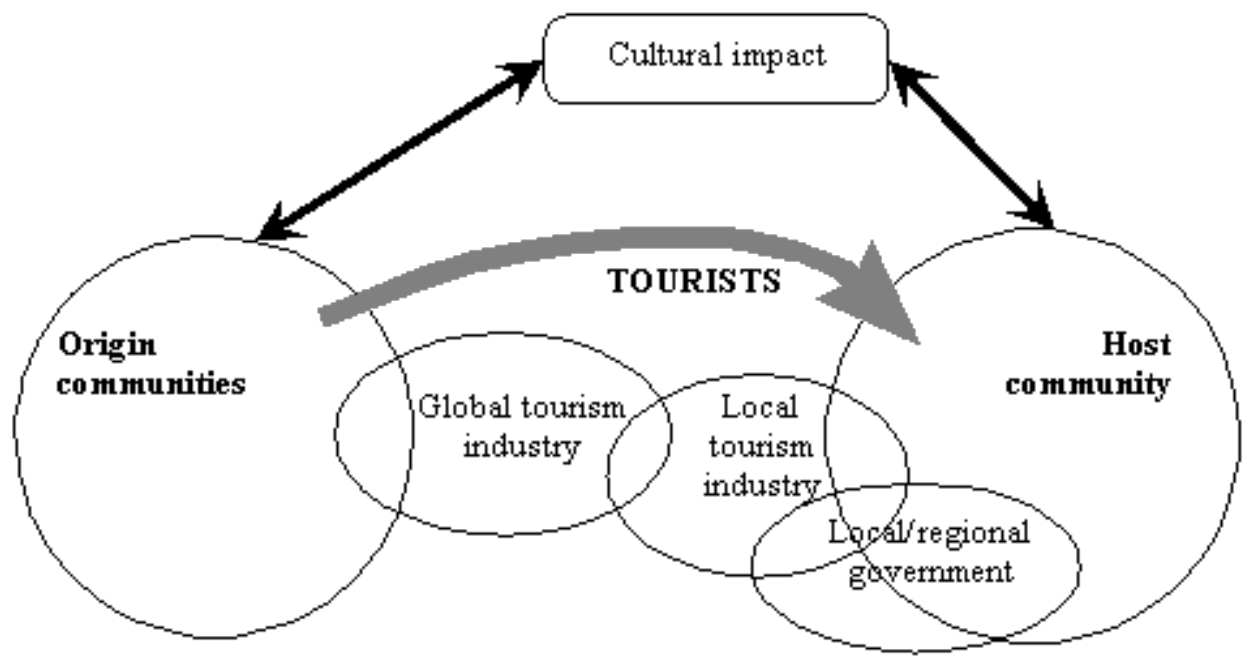

Figure 1. Cultural Model 


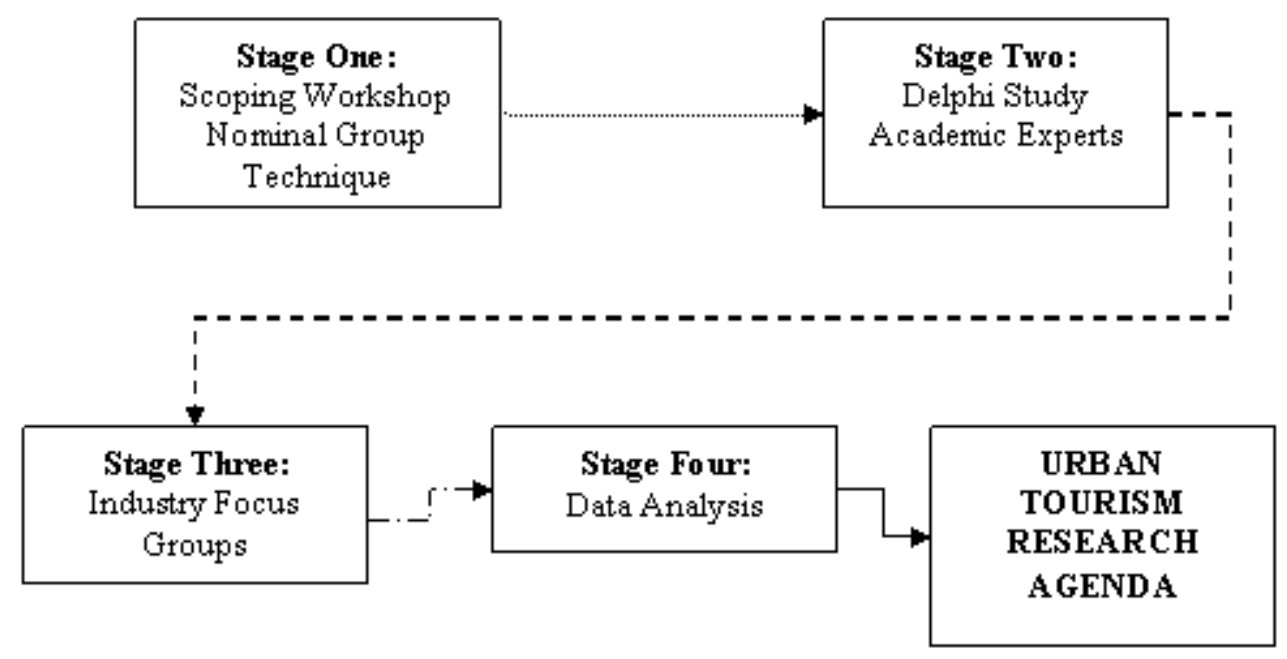

Figure 2. Framework for Developing an Urban Tourism Research Agenda 
Table 1. Top Ten Issues Identified in the Delphi Study

\begin{tabular}{|c|c|c|c|c|}
\hline Rank & Theme* & Issue & $\mathbf{N}$ & Mean $^{\text {ab }}$ \\
\hline 1 & $\mathrm{E} \& \mathrm{~B}$ & Examine how tourists use cities & 12 & 1.5 \\
\hline 2 & $\mathrm{E} \& \mathrm{~B}$ & Identify the patterns of behavior of tourists in cities & 12 & 1.6 \\
\hline 3 & I & $\begin{array}{l}\text { Understand the environmental impacts currently occurring within urban } \\
\text { destinations. }\end{array}$ & 12 & 1.8 \\
\hline 4 & SR & $\begin{array}{l}\text { Analyze the influence that transport to cities has on tourist access and } \\
\text { numbers }\end{array}$ & 12 & 2.0 \\
\hline 5 & I & Identify the benefits of urban tourism to the local community & 12 & 2.0 \\
\hline 6 & DDM & $\begin{array}{l}\text { Identify the criteria for successful urban tourism destination } \\
\text { development }\end{array}$ & 12 & 2.0 \\
\hline 7 & I & Understand the carrying capacity of urban tourism precincts & 12 & 2.0 \\
\hline 8 & I & $\begin{array}{l}\text { Understand the impacts tourists have on the leisure experience, spaces } \\
\text { and places of the local community }\end{array}$ & 12 & 2.0 \\
\hline 9 & SR & $\begin{array}{l}\text { Examine the linkages between attractions and how they disperse tourists } \\
\text { within urban tourism destinations }\end{array}$ & 12 & 2.1 \\
\hline 10 & DDM & Identify national and international best practices for urban tourism & 12 & 2.1 \\
\hline
\end{tabular}

${ }^{\mathrm{a}}$ Lower scores indicate higher levels for each item; ${ }^{\mathrm{b}}$ Scale Range $1-7$ for each item.

* E\&B - Experience and behavior issues; I - Impacts; SR - Spatial relationship issues; DDM - Destination development and management issues. 
Table 1. Top Ten Issues Identified in the Delphi Study

\begin{tabular}{|c|c|c|c|c|c|c|}
\hline \multicolumn{4}{|c|}{ Academic Ranking (N=12) } & \multicolumn{3}{|c|}{ Industry Ranking ( $=24)$} \\
\hline $\begin{array}{l}\text { Rank } \\
\text { order }\end{array}$ & Theme* & Issue & Mean $^{\mathrm{ab}}$ & Theme* & Issue & Mean $^{\text {ab }}$ \\
\hline 1 & $\mathrm{E} \& \mathrm{~B}$ & Examine how tourists use cities. & 1.5 & SR & $\begin{array}{l}\text { Analyse the influence that transport to cities has on } \\
\text { tourist access and numbers. }\end{array}$ & 2.5 \\
\hline 2 & $\mathrm{E} \& \mathrm{~B}$ & $\begin{array}{l}\text { Identify the patterns of behaviour of tourists in } \\
\text { cities. }\end{array}$ & 1.6 & $\mathrm{I}$ & $\begin{array}{l}\text { Identify the benefits of urban tourism to the local } \\
\text { community. }\end{array}$ & 2.5 \\
\hline 3 & I & $\begin{array}{l}\text { Understand the environmental impacts currently } \\
\text { occurring within urban destinations. }\end{array}$ & 1.8 & DDM & $\begin{array}{l}\text { Identify the criteria for successful urban tourism } \\
\text { destination development. }\end{array}$ & 2.5 \\
\hline 4 & SR & $\begin{array}{l}\text { Analyse the influence that transport to cities has on } \\
\text { tourist access and numbers }\end{array}$ & 2.0 & $\mathrm{E} \& \mathrm{~B}$ & Identify the patterns of behaviour of tourists in cities. & 2.7 \\
\hline 5 & I & $\begin{array}{l}\text { Identify the benefits of urban tourism to the local } \\
\text { community. }\end{array}$ & 2.0 & DDM & $\begin{array}{l}\text { Identify national and international best practices for } \\
\text { urban tourism. }\end{array}$ & 2.8 \\
\hline 6 & $\mathrm{DDM}$ & $\begin{array}{l}\text { Identify the criteria for successful urban tourism } \\
\text { destination development }\end{array}$ & 2.0 & I & $\begin{array}{l}\text { Understand the impacts tourists have on the leisure } \\
\text { experience, spaces and places of the local } \\
\text { community. }\end{array}$ & 2.9 \\
\hline 7 & I & $\begin{array}{l}\text { Understand the carrying capacity of urban tourism } \\
\text { precincts. }\end{array}$ & 2.0 & $\mathrm{E} \& \mathrm{~B}$ & Examine how tourists use cities. & 3.0 \\
\hline 8 & I & $\begin{array}{l}\text { Understand the impacts tourists have on the leisure } \\
\text { experience, spaces and places of the local } \\
\text { community. }\end{array}$ & 2.0 & I & $\begin{array}{l}\text { Understand the environmental impacts currently } \\
\text { occurring within urban destinations. }\end{array}$ & 3.2 \\
\hline 9 & SR & $\begin{array}{l}\text { Examine the linkages between attractions and how } \\
\text { they disperse tourists within urban tourism } \\
\text { destinations. }\end{array}$ & 2.1 & I & $\begin{array}{l}\text { Understand the carrying capacity of urban tourism } \\
\text { precincts. }\end{array}$ & 3.4 \\
\hline 10 & $\mathrm{DDM}$ & $\begin{array}{l}\text { Identify national and international best practices for } \\
\text { urban tourism. }\end{array}$ & 2.1 & SR & $\begin{array}{l}\text { Examine the linkages between attractions and how } \\
\text { they disperse tourists within urban tourism } \\
\text { destinations. }\end{array}$ & 3.6 \\
\hline
\end{tabular}

${ }^{\mathrm{a}}$ Lower scores indicate higher levels for each item; ${ }^{\mathrm{b}}$ Scale Range 1 - 7 for each item.

* E\&B - Experience and behavior issues; I - Impacts; SR - Spatial relationship issues; DDM - Destination development and management issues. 


\section{Positive Outcomes}

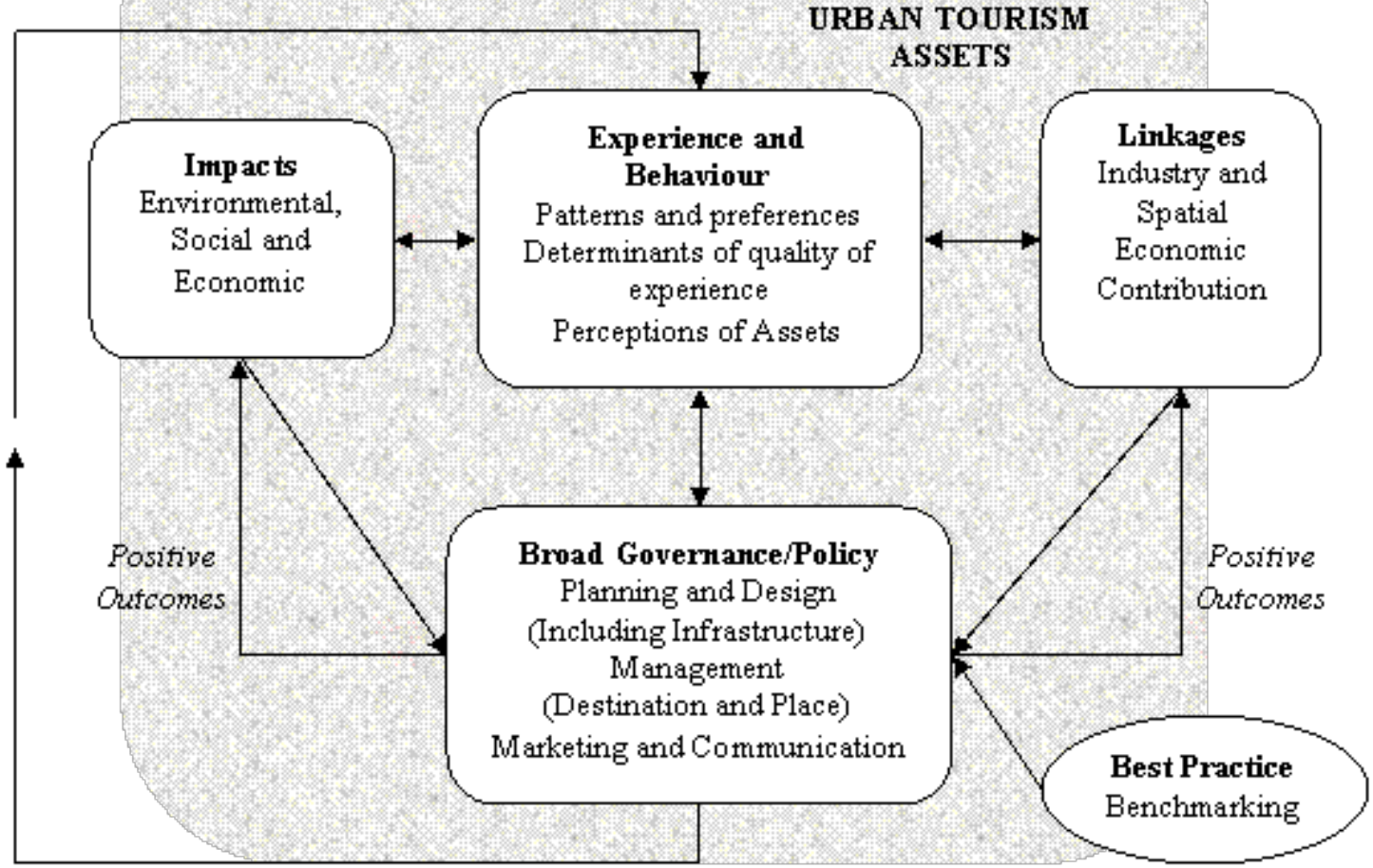

Positive Outcomes

TRENDS MACRO

Figure 3. Strategic Framework for Urban Tourism Research 


\section{REFERENCES}

Aaker, D., V. Kumar, and G. Day.

2003 Marketing Research. New York: John Wiley \& Sons, Inc.

Ashworth, G.J.

1989 Urban Tourism: An Imbalance in Attention. In Progress in Tourism Recreation and Hospitality

Management, C.P. Cooper, ed., vol. 1, pp. 33-54. London: Belhaven.

Ashworth, G.J., and J.E. Tunbridge

1990 The Tourist-Historic City. London: Belhaven.

2000 The Tourist-Historic City: Retrospect and Prospect of Managing the Heritage City. Oxford: Pergamon,

Elsevier Science Ltd.

Blank, U.

1994 Research on Urban Tourism Destinations. In Travel, Tourism, and Hospitality Research, J.R.B. Ritchie and C.R. Goeldner, eds., pp. 181-196. New York: John Wiley.

Blank, U., and M. Petkovich.

1979 The Metropolitan Area Tourist: A Comprehensive Analysis. Traven and Tourism Research

Association, A Decade of Achievement, Proceedings, pp. 227-236. Boise, ID: TTRA.

Burgess, J.A.

1975 Selling Places. Regional Studies 16(1):1-17.

Delbecq, A.L., A.H. Van de Ven, and D. Gustafson

1975 Group Techniques for Program Planning: A Guide to the Nominal Group and Delphi Process.

Glenview, IL: Scott Foresman Company.

Fainstein, S.S.

1994 The City Builders: Property, Politics, and Planning in London and New York. Oxford: Blackwell.

Fainstein, S.S., and D. Gladstone

1997 Tourism and Urban Transformation: Interpretations of Urban Tourism. In Cities in Transformation Transformation in Cities: Social and Symbolic Change in Urban Space, O. Källtorp, I. Elander, O.

Ericsson and M. Franzén, eds., pp. 119-135. Aldershot, Hants: Avebury.

Garrod, B., and A. Fyall

2005 Revisiting Delphi: The Delphi Technique in Tourism Research. In Tourism Research Methods:

Integrating Theory with Practice, B.W. Ritchie, P. Burns and C. Palmer, eds., pp. 85-98. Cambridge, Mass: Longman.

Gomm, R.

2004 Social Research Methodology: A Critical Introduction. New York: Palgrave Macmillan.

Gospodini, A.

2001 Urban Design, Urban Space Morphology, Urban Tourism: An Emerging Paradigm Concerning Their Relationship. European Planning Studies 9(7):925-934.

Grabler, K., G. Maier, J. Mazanec, and K. Wöber, eds.

1997 International City Tourism: Analysis and Strategy. London: Pinter.

Hall, P.

1987 Urban Development and the Future of Tourism. Tourism Management 8(2):129-130.

Hayllar, B., A. Griffin, and D. Edwards, eds.

2008 City Spaces -Tourist Places: Urban Tourism Precincts. Oxford: Butterworth-Heinemann.

Judd, D.R., and M. Collins 
1979 The Case of Tourism: Political Coalitions and Redevelopment in Central Cities. In The Changing Structure of Cities: What Happened to the Urban Crisis?, G. Tobin, ed., pp. 177-199. Beverly Hills, CA: Sage.

Judd, D.R., and S.S. Fainstein, eds. 1999 The Tourist City. New Haven, CT: Yale University Press.

Karski, A.

1990 Urban Tourism: A Key to Urban Regeneration? The Planner 76(13):15-17.

Krueger, R.

1998 Designing and Conducting Focus Group Interviews: Seminar Notes. Bankstown, Sydney: University of Western Sydney.

Law, C.M.

1993 Urban Tourism: Attracting Visitors to Large Cities. London: Mansell.

1996 Tourism in Major Cities. London: International Thompson Business Press/ Routledge.

Linstone, H.A., and M. Turoff.

1975 The Delphi Method: Techniques and Applications. place: Addison-Wesley Publishing Co.

Lynch, K.

1960 The Image of the City. Cambridge, Mass: MIT Press.

McIntyre, N.E., K. Knowles-Yánez,and D. Hope. 2000 Urban Ecology as an Interdisciplinary Field: Differences in the Use of "Urban” between the Social and Natural Sciences. Urban Ecosystems 4:5-24.

Merton, R.K., M. Fiske, and P.L. Kendall. 1990 The Focused Interview. New York: Free Press.

Murphy, P.E., ed. 1996 Quality Management in Urban Tourism. New York: Wiley.

Murray, T.J. 1979 Delphi Methodologies: A Review and Critique. Urban Systems 4:153-158.

Orbasli, A.

2000 Tourists in Historic Towns: Urban Conservation and Heritage Management. London: Spon Press.

Page, S.

1995 Urban Tourism. London: Routledge.

1996 Urban Heritage Tourism in New Zealand: The Wellington Waterfront Development in the 1990s. In Heritage Management in Australia and New Zealand: The Human Dimension, C.M. Hall and S.McArthur, eds., pp. 17-20. Melbourne: Oxford University Press. 2000 Urban Tourism: Introduction. In Tourism Management: Towards the New Millennium, C. Ryan and S. Page, eds., pp. 197-201. Oxford: Pergamon.

Pearce, D.

2001 An Integrative Framework for Urban Tourism Research. Annals of Tourism Research 28(4):926-946.

Pearce, D.G.

1987 Tourism Today: A Geographical Analysis. Harlow, Essex: Longman.

Pearce, P.L.

1977 Mental Souvenirs: A Study of Tourists and Their City Maps. Australian Journal of Psychology 29:203-210.

Presbury, R., and D. Edwards. 
2005 Incorporating Sustainability in Meetings and Event Management Education. International Journal of Event Management Research 1(1):30.

Rowe, G., and G. Wright

2002 Expert Opinions in Forecasting: The Role of the Delphi Technique. In Principles of Forecasting: A Handbook for Researchers and Practitioners, J.S. Armstrong, ed., pages. Hingham, MA: Kluwer Academic Publishers.

Statistics New Zealand.

2006 Defining Urban and Rural New Zealand < $\underline{\text { http://www.stats.govt.nz/urban-rural-profiles/defining- }}$ urban-rural-nz/default.htm> Sourced (20 October 2005).

Thomas, K.

2004 The Research Process as a Journey: From Positivist Traditions into the Realms of Qualitative Inquiry. In Qualitative Research in Tourism: Ontologies, Epistemologies and Methodologies, J. Phillimore and L. Goodson, eds., pp. 333-346. London: Routledge.

Tyler, D., Y. Guerrier, and M. Robertson, eds.

1998 Managing Tourism in Cities: Policy, Process, and Practice. Chichester, West Sussex: John Wiley.

United Nations

1968 Demographic Handbook for Africa. Addis Ababa, Ethiopia: United Nations Economic Commission for Africa.

Van den Burg, L., J. Van der Borg, and J. Van der Meer

1995 Urban Tourism Performance and Strategies in Eight European Cities. Aldershot: Avebury. 